\title{
UPAYA PENINGKATAN KUALITAS SEKOLAH MELALUI PEMBUATAN DAN PENGELOLAAN WEBSITE SEKOLAH \\ (Studi Kasus di Sekolah Muhammadiyah se Kecamatan Polokarto Kabupaten Sukoharjo)
}

\author{
Fuad Anwar $^{1)}$, Mohtar Yunianto ${ }^{1)}$, Agus Purnomo ${ }^{2)}$, Rudi Hartono ${ }^{2)}$ \\ Program Studi Fisika, Universitas Sebelas Maret Surakarta \\ Program D3 Teknik Informatika, Universitas Sebelas Maret Surakarta \\ Email : mohtaryunianto@staff.uns.ac.id
}

\begin{abstract}
ABSTRAK
Telah dilakukan upaya peningkatan kualitas Sekolah Muhammadiyah se-kecamatan Polokarto Kabupaten Sukoharjo, upaya yang dilakukan adalah berupa pembuatan website serta pelatihan pengelolaan website. Hasil yang diperoleh telah dikelola dengan baik sebanyak 16 website sekolah Muhammadiyah sebagai sarana untuk promosi sekolah yang lebih efektif dan menjangkau lebih luas.
\end{abstract}

Kata kunci : website, sekolah, kualitas, Teknologi Informasi

\section{PENDAHULUAN}

Teknologi informasi dalam dunia pendidikan sangatlah penting. Di era globalisasi ini peran teknologi dan informasi mempunyai peranan yang sangat penting dan vital. Dengan menguasai teknologi dan informasi, kita memiliki modal yang sangat cukup untuk menjadi pemenang dalam persaingan global. Di era globalisasi ini tidak menguasai teknologi informasi identik dengan sebutan gaptek bahkan buta huruf (Jaultop, 2017). Dengan berkembangnya Teknologi Informasi, dunia pendidikan mulai memperlihatkan perubahan yang cukup signifikan. Ada perubahan-perubahan cara mengajar yang berkembang dalam dunia pendidikan, sekarang ini, jarak dan waktu bukanlah sebagai masalah yang berarti untuk transfer ilmu pengetahuan, banyak software dan aplikasi yang dibuat untuk memfasilitasi dalam transfer pengetahuan ini.

Dalam bidang pendidikan, teknologi dan informasi telah mengubah paradigma penyampaian materi yang berbeda kepada peserta didik. Penekanan penting akan memaksimalkan SDM di berbagai sektor. Hal itu berarti kita membutuhkan sistem komunikasi yang sangat efektif (Wulandari, 2017). Apabila kita merespons pada kebutuhan fokus awal, seharusnya lebih berdasarkan penerimaan informasi daripada penyebaran informasi. Hal inilah yang memutar balikkan peran jika kita dibandingan dengan peran komunikasi administrasi pendidikan yang dulu.

Kemampuan yang pesat di bidang ilmu pengetahuan dan teknologi di negara maju karena memang didukung dengan sistem informasi yang sudah matang dan mapan. Namun sebaliknya sistem informasi yang masih lemah di negara - negara yang masih berkembang mengakibatkan ketertinggalan dan keterbelakangan dalam penguasaan ilmu pengetahuan dan juga teknologi termasuk juga Multimedia. Jelas bahwa maju atau tidaknya sebuah negara sangat ditentukan oleh penguasaan terhadap Teknologi dan informasi karena informasi merupakan senjata pokok untuk membangun Negara (Jaultop, 2017).

Apabila kita lihat dari perkembangan dunia pendidikan sekarang media teknologi informasi mungkin sudah merambah keberbagai daerah akses terhadap sumber informasi bukan menjadi masalah lagi yang mungkin lebih dikenal sekarang ini dengan nama internet, internet merupakan media komunikasi yang paling cocok dalam pembelajaran. karena 
merupakan sumber informasi yang paling lengkap untuk mengetahui berbagai pengetahuan yang ada diluar. Sehingga dengan media informasi ini kita sebagai pemakai dapat memanfaatkan semaksimal mungkin untuk dapat meningkatkan kemampuan kita. Diharapkan dari adanya teknologi informasi kita mungkin bisa mengembangkan atau menciptakan hal-hal yang baru yang dapat bermanfaat bagi bangsa dan negara. Manfaat teknologi informasi bangsa kita bisa maju sejajar dengan bangsa-bangsa yang sudah maju.

Media komunikasi maupun media promosi yang paling efektif saat ini adalah website (Jauzal, 2014), dalam website tersebut dapat ditampilkan data-data suatu instansi, keunggulan serta informasi-informasi yang terbaru sehingga masyarakat luas dapat lebih mengenal keberadaan instansi tersebut tanpa harus berkunjung secara langsung.

\section{METODE PELAKSANAAN}

Di dalam proses pemberian informasi mengenai kondisi dan faslitasi seuatu sekolah selama ini mengguanakn media leaflet, pamlet dan berkunjung kesekolah-sekolah di bawahnya, hal ini sangat tidak efektif karena memerlukan waktu dan biaya yang banyak, oleh karena itu perlu dilakukan upaya untuk mengantisipasi hal ini yaitu dengan pembuatan dan pengembangan website sekolah yang interaktif sehingga lebih efektif, efisien dan mudah dalam memberikan informasi keberadaan suatu sekolah dengan lebih cepat.

Untuk mewujudkan target utama dari kegiatan ini yaitu adanya usaha untuk mengenalkan serta dapat mengelola website sebagai sarana promosi dan juga mengembangkan database sekolah, maka metode pelaksanaan kegiatan dibuat dalam bentuk sebagai berikut :

a. Kegiatan berupa pembuatan website untuk Dikdasmen serta membuat subdomain untuk seluruh sekolah yang berada di bawah dikdasmen Muhammadiyah Cabang Blimbing sebanyak ada 16 sekolah.

b. Pelatihan pengelolaan website yang diikuti oleh admin IT masing-masing sekolah

c. Pengelolaan dan perawatan website oleh masing-masing sekolah

\section{HASIL DAN PEMBAHASAN}

Pembuatan domain dan hosting untuk induk dari website tersebut yang beralamat di https://dikdasmenblimbing.org. Website tersebut berisi tentang profil, Undang-undang / peraturan, Undangan / informasi, Pengumuman, Kegiatan / pelatihan serta link meunju ke wesite Sekolah-sekolah yang berada di bawah dikdasmen. Tampilan dari website dikdasmen adalah sepertio pada Gambar 1 berikut

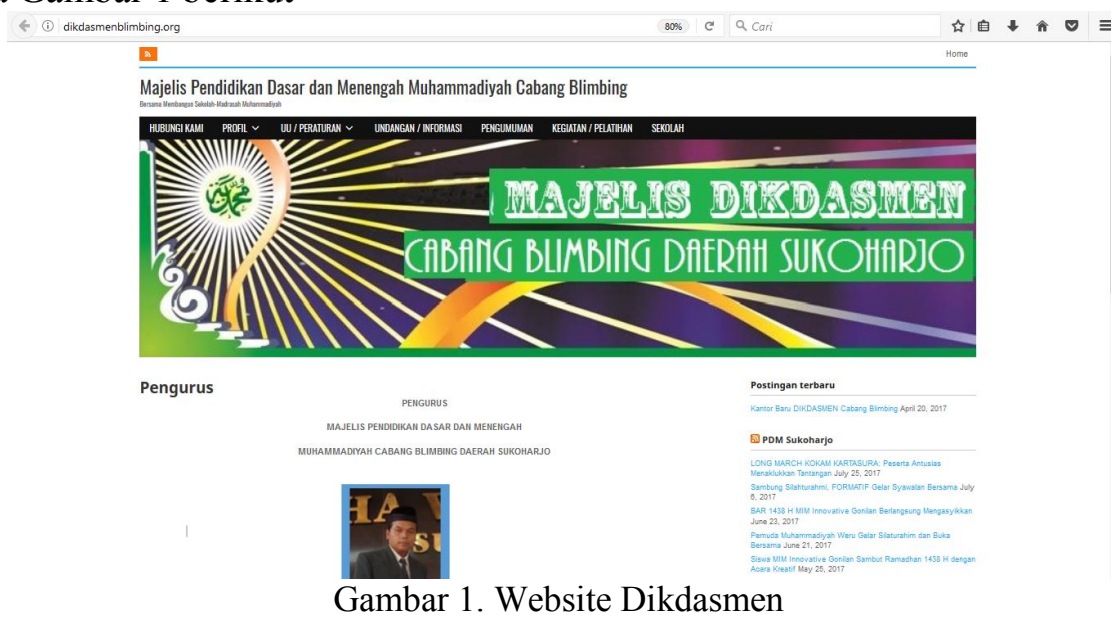

Website induk dikelola oleh admin dari Majelis Pendidikan Dasar dan Menengah yang membawahi sekolah-sekolah Muhammadiyah se-Kecamatan Polokarto. Setelah website induk 
selesai dibuat dan di kelola dengan baik, kemudian dibuat subdomain di bawah web utama tersebut webste-website sekolah sebanyak 16 web, dengan alamat sebagai berikut :

1. mimwonorejo.dikdasmenblimbing.org

2. mimjatisobo.dikdasmenblimbing.org

3. mimkemasan.dikdasmenblimbing.org

4. mimngombakan.dikdasmenblimbing.org

5. mimgodog.dikdasmenblimbing.org

6. mimtanjung.dikdasmenblimbing.org

7. mimkarangwuni.dikdasmenblimbing.org

8. mimmiri.dikdasmenblimbing.org

9. mimngrobyong.dikdasmenblimbing.org

10. mimlemahbang.dikdasmenblimbing.org

11. sdmwonorejo.dikdasmenblimbing.org

12. sdmimamsyuhodo.dikdasmenblimbing.org

13. mtsmblimbing. dikdasmenblimbing.org

14. smpmwonorejo.dikdasmenblimbing.org

15. smamimamsyuhodo.dikdasmenblimbing.org

16 smkmimamsyuhodo.dikdasmenblimbing.org

16 website tersebut telah dikelola dengan baik oleh admin masing-masing sekolah, terlebih dahulu admin diberi pelatihan dalam pengelolaan website, dimana suasana pelatihan terllihat pada Gambar 2, sedangkan materi-materi dalam pelatihan yang diberikan meliputi :

1. Mengenal Webblog,

2. Create Category, Posting

3. Mengelola Tag/Kata Kunci,

4. Mengelola Link,

5. Mengelola Blogroll,

6. Mengelola Gambar,

7. Mengelola Video,

8. Mengelola Widget,

9. Mengelola Themes,

10. Mengelola Sidebar, Rss,

11. Membuat Status Ym, facebook dan twitter Di Webblog.

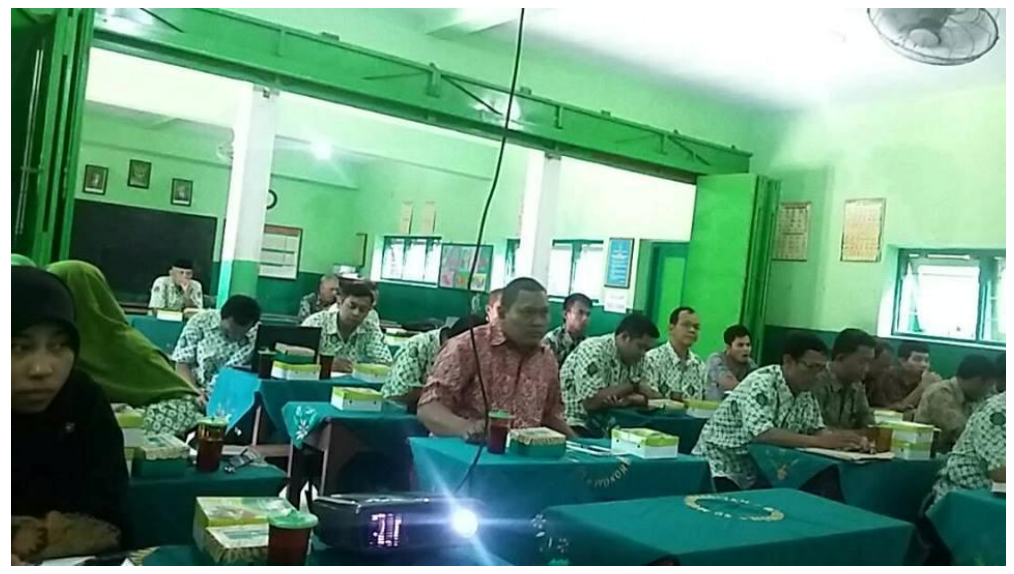

Gambar 2. Suasana pelatihan Website Sekolah

Sebagian sekolah sudah dapat melakukan pengelolan website sekolah dengan baik dengan hasil setelah pelaksanaan pelatihan tersaji dalam tabel 2 berikut. 
Tabel 2. Hasil pengelolaan website sekolah

\begin{tabular}{|r|l|l|l|l|}
\hline No & \multicolumn{1}{|c|}{ Sekolah } & \multicolumn{1}{|c|}{ Status } & Update Info & \multicolumn{1}{c|}{$\begin{array}{c}\text { Update } \\
\text { Desain }\end{array}$} \\
\hline 1 & MIM Wonorejo & AKTIF & YA & YA \\
\hline 2 & MIM Jatisobo & AKTIF & YA & YA \\
\hline 3 & MIM Kemasan & AKTIF & YA & YA \\
\hline 4 & MIM Ngombakan & AKTIF & YA & YA \\
\hline 5 & MIM Godog & AKTIF & BELUM & YA \\
\hline 6 & MIM Tanjung & AKTIF & YA & YA \\
\hline 7 & MIM Karangwuni & AKTIF & YA & YA \\
\hline 8 & MIM Miri & AKTIF & YA & YA \\
\hline 9 & MIM Ngrobyong & AKTIF & YA & YA \\
\hline 10 & MIM Lemahbang & AKTIF & YA & YA \\
\hline 11 & SDM Wonorejo & AKTIF & YA & YA \\
\hline 12 & SDM Imam Syuhodo & AKTIF & YA & YA \\
\hline 13 & MTS Mblimbing & AKTIF & YA & YA \\
\hline 14 & SMP M Wonorejo & AKTIF & BELUM & YA \\
\hline 15 & SMA Imam Syuhodo & AKTIF & YA & YA \\
\hline 16 & SMK Imam Syuhodo & AKTIF & YA & YA \\
\hline
\end{tabular}

Aadapun Beberapa contoh tampilan website sekolah Muhammdiyah dalah seperti pada Gambar 3-6 berikut.

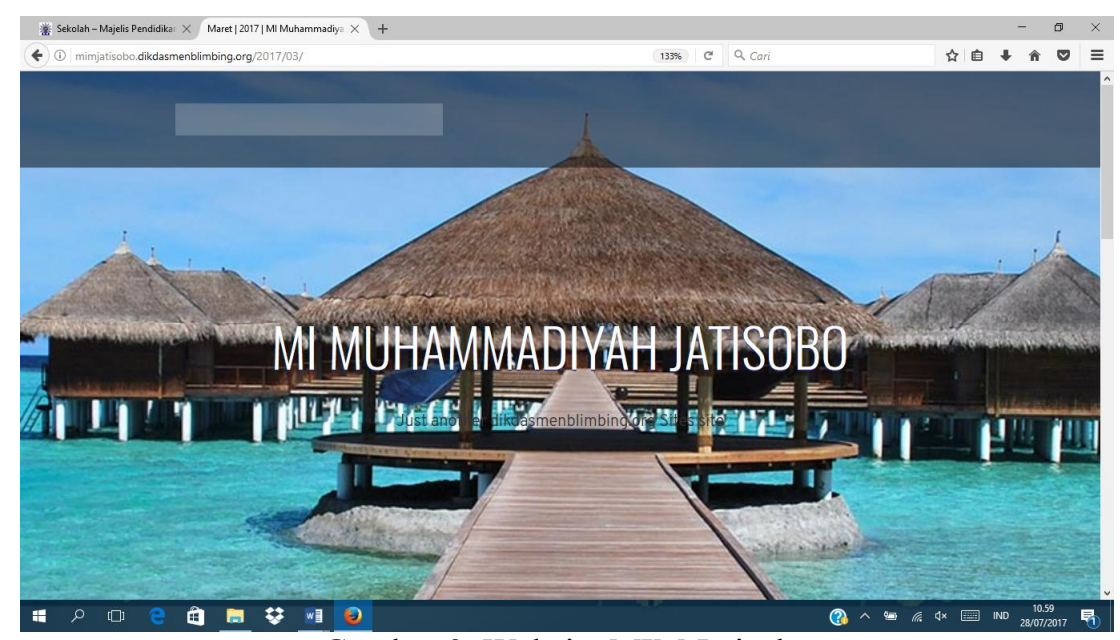

Gambar 3. Website MIM Jatisobo 


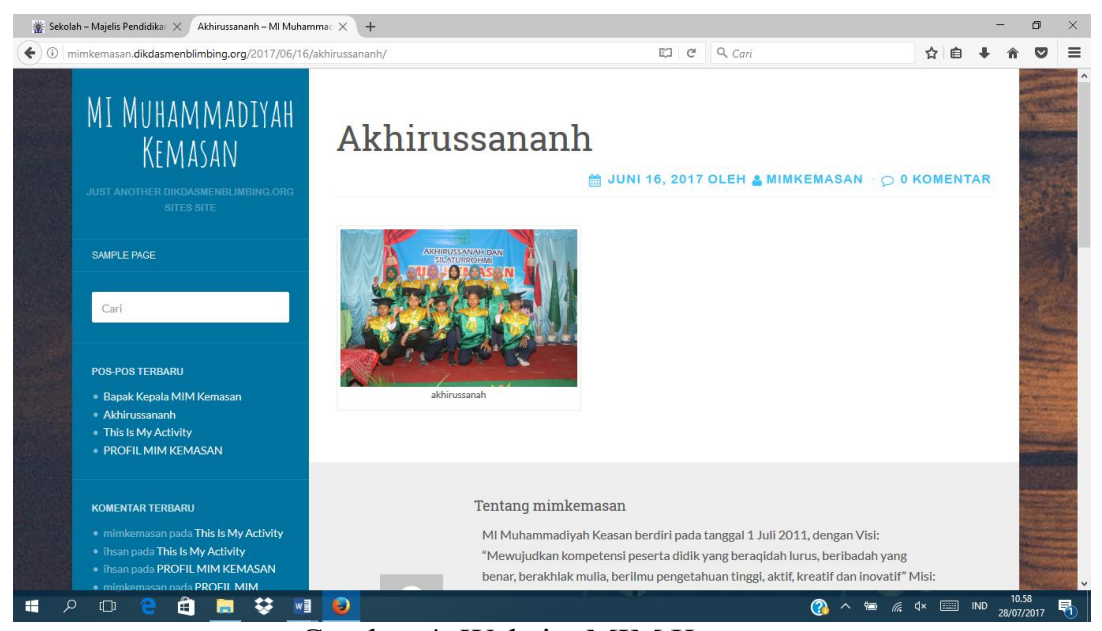

Gambar 4. Website MIM Kemasan
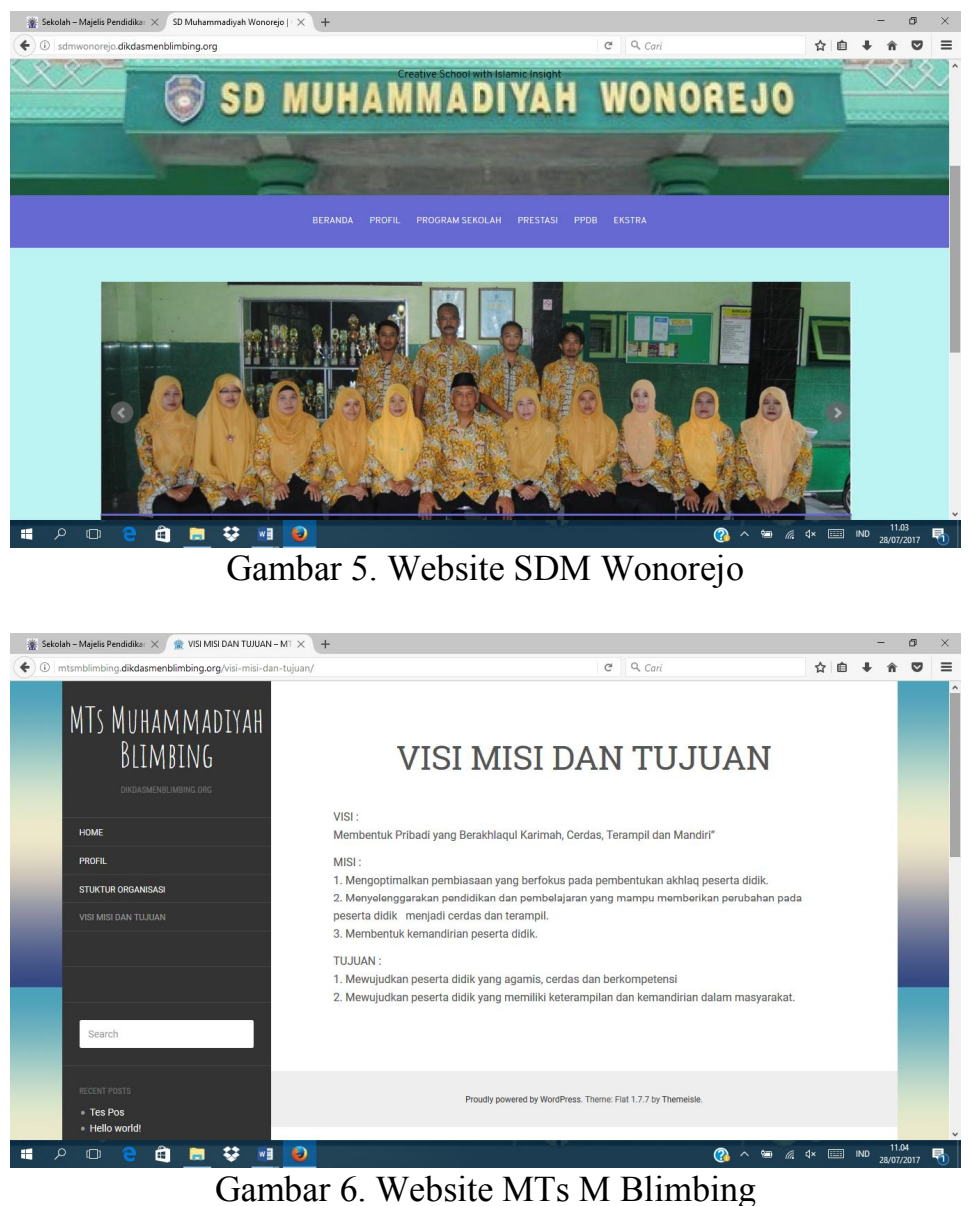

\section{KESIMPULAN}

Dari pelaksanaan kegiatan berupa pembuatan website untuk Majelis Dikdasmen Muhammadiyah Cabang Blimbing serta 16 subdomain untuk Sekolah Muhammadiyah seCabang Blimbing serta pelaksanaan pelatihan pengelolaan website diperoleh hasil bahwa masing-masing Sekolah telah dapat mengelola website dengan baik, baik dalam melakukan update content maupun update tampilan, harapannya nantinya dengan media website ini dapat lebih mengenalkan sekolah-sekolah tersebut ke masyarakat luas. 


\section{DAFTAR PUSTAKA}

Jaultop Sitio, 2017, Peranan Teknologi Informasi Dalam Dunia Pendidikan, diakses dari https://www.masukuniversitas.com/teknologi-informasi-dalam-dunia-pendidikan/ pada 30 Juli 2017

Wulandari, Eko Nugroho, 2017, E-Learning : Implikasinya Terhadap Pelayanan Perpustakaan Perguruan Tinggi Dan Peran Pustakawan, Berkala Ilmu Perpustakaan Dan Informasi, Vol. 13, No. 1, Juni 2017, Hal. 87-96.

Jazaul Aufa, 2014, Efektivitas Website Sebagai Media Komunikasi Pemasaran Kampoeng Wisata Bisnis Tegalwaru, Ciampea, Bogor, Jawa Barat, Skripsi, 